\title{
ÉTICA MERCADOLÓGICA EN UN MARCO DE RESPONSABILIDAD SOCIAL CORPORATIVA
}

\author{
MARKETING ETHICS IN A FRAMEWORK \\ OF CORPORATE SOCIAL RESPONSIBILITY
}

Ricardo Arturo Valdez Cornejo

Gloval, Consultoría y Asesoría Empresarial, Arequipa, Perú

\section{Resumen:}

El presente trabajo trata acerca de resaltar la importancia de la ética en la actividad mercadológica y, por tanto, en la actividad empresarial. En un mundo globalizado, en el que no es extraño encontrar posiciones y acciones que atentan contra el ser humano y su integridad; es importante recurrir a los valores en alza y a los principios rectores que deben ser cimiento y columna vertebral de toda actividad corporativa, especialmente en lo que respecta al marketing. Asimismo, se ha demostrado que la ética y la responsabilidad social generan, a la postre, ganancias para la empresa, la cual será mejor vista por la sociedad si practica con sinceridad valores redituables, haciendo de la labor empresarial una actividad sostenible y sustentable.

Palabras clave: Mercadotecnia, ética, valores, responsabilidad social corporativa, grupos de interés.

\section{Summary:}

The present work is about emphasizing the importance of ethics in marketing activity and, therefore, in the business. In a globalized world, in which it is not strange to find positions and actions that threaten the human being and its integrity; it's important to have the values and guiding principles which should be Foundation and backbone of all corporate activities, especially with regard to marketing. Also, it has been shown that ethics and social responsibility generated many profits for the company, which 
will have a better view by society if the company practices with sincerity profitable values, making the business work a sustainable activity.

Key words: Marketing, ethics, values, corporate social responsibility, stakeholders.

"El desarrollo humano, como enfoque, se ocupa de lo que yo considero la idea básica de desarrollo: concretamente, el aumento de la riqueza de la vida humana en lugar de la riqueza de la economía en la que los seres humanos viven, que es sólo una parte de la vida misma”.

Amartya Sen

Universidad de Harvard, Premio Nobel de Economía, 1998

La economía, la administración y otras ramas del conocimiento ligadas al quehacer empresarial, son ciencias complejas que abordan aspectos materiales y humanos, siendo estos últimos los más descuidados en la práctica. Por esta razón es importante humanizar las disciplinas y saberes mencionados. Dentro de la humanización se encuentra, por supuesto, el hecho de incorporar la ética como elemento inseparable de la actividad empresarial y al interior de ésta, la actividad mercadológica. Asimismo, es fundamental considerar que la economía está al servicio del ser humano, y no al revés.

En diversas oportunidades hemos sido testigos de cómo se puede llegar a atentar contra el desarrollo humano cuando los mercadólogos no miden las consecuencias de sus actos, guiados únicamente por un sentido mercantilista, a su vez, alimentado por las presiones en crecimiento provenientes de intereses corporativos que buscan lucro desmedido que linda o, incluso, supera los límites de la crematística, posición duramente condenada por los filósofos socráticos y, concretamente por
Aristóteles, quien consideraba el excesivo afán de lucro como una actividad antinatural y deshumanizante. Posteriormente, Santo Tomás de Aquino, indicó que la acumulación de la riqueza puede ser válida si ésta se pone al servicio de la caridad.

Por estas razones, es importante que cada profesional en marketing conozca realmente cuáles son sus límites en lo económico y en el actuar mercadológico, de tal forma que no se atente contra la ética, las buenas costumbres, la tranquilidad, y en extremo; contra la sociedad en su conjunto.

Los enfoques acerca de esta actividad empresarial son sumamente amplios y diversos. Uno de éstos es el que menciona Philip Kotler, reconocido como el gurú del marketing moderno, y en el que se indica que la mercadotecnia es un proceso que se da en sociedad y además es de carácter administrativo, mediante el cual grupos e individuos obtienen lo que necesitan y desean a través de generar, ofrecer e intercambiar productos de valor con otros, entendiendo como productos tanto a los bienes tangibles como a los servicios. 
Como se puede apreciar, este concepto está dirigido a lo administrativo y a lo comercial. Habla de intercambio, de cubrir necesidades y de generar valor. Sin embrago, cabe resaltar -y aquí viene la primera discrepancia con el autor-que este concepto no es de ninguna manera completo, ya que excluye un elemento fundamental que es la realización más allá de la cobertura de necesidades y satisfacción de deseos, puntos clave estos, en los que se sustenta la actividad mercadológica y comercial de las empresas. Cabe resaltar que Kotler, al hablar de marketing 3.o, años después a las primeras ediciones de su libro; toca puntos importantes como generación y maximización de valor compartido, así como de responsabilidad social; no obstante, estos criterios debieran incluirse en su concepto básico de marketing, como los elementos principales.

De hecho, el ser humano necesita satisfacer deseos y cubrir necesidades, pero más allá de los aspectos meramente físicos se encuentran los espirituales que van en escala creciente, lo cual ya fue demostrado hace mucho tiempo. Todas estas necesidades, según Abraham Maslow se agrupan en cinco categorías: Necesidades fisiológicas, de seguridad, sociales, de estima, de autorrealización (Chiavenato, 2005).

Obsérvese que a partir de las necesidades de seguridad en adelante, éstas van dejando las dimensiones físicas para adoptar otras más trascendentes y cada vez menos materiales, por lo que se convierten en necesidades relacionadas con el desarrollo humano integral.
Ahora bien, si se quiere analizar con mayor profundidad la actividad mercadotécnica, se puede citar nuevamente a Kotler, quien indica que:

Hoy en día, debemos entender la mercadotecnia no sólo en el sentido más antiguo de concretar ventas, sino en el nuevo sentido de cubrir las necesidades y satisfacer los deseos de los compradores o clientes. Si la empresa hace una buena labor al comprender las necesidades del cliente, desarrolla productos que proporcionan un valor superior, determina precios adecuados, distribuye eficientemente y comunica en forma efectiva, esos productos se venderán con gran facilidad. En tal sentido, las ventas y la comunicación sólo son parte de una «mezcla de mercadotecnia», que funcionan como instrumentos de mercadotecnia que operan conjuntamente para tener éxito en el mercado. (Kotler y Armtrong, 2013, p. 23)

Es claro nuevamente, que en esta ampliación del concepto de mercadotecnia se excluyen elementos sumamente importantes que debieran ser tomados muy en cuenta, y en tal sentido, es pertinente. El primer y más importante elemento, que es motivo de análisis en este documento, es la ética que implica responsabilidad social -la cual, hoy en día es un concepto inseparable de toda actividad empresarial seria- así como la generación de valor agregado y de relaciones duraderas entre empresas y clientes. Estas relaciones duraderas se darán como efecto de la actitud positiva permanente que tenga la empresa respecto a sus clientes y sociedad en general.

Efectivamente, se debe incidir que la responsabilidad social es una cuestión de 
actitud de los empresarios en un ámbito de desarrollo organizacional y social. Todo empieza por un cambio a este nivel. Además, la responsabilidad social corporativa genera beneficios económicos a largo plazo, al otorgarle a la empresa sustentabilidad y sostenibilidad en el tiempo. En tal sentido, se requiere el desarrollo de una visión amplia en cuanto a responsabilidad social corporativa como parte de una gestión integrada y, por tanto, generar diferenciación en un mercado cada vez más competitivo.

A la postre, es el cliente quien premiará con su fidelidad a la empresa socialmente responsable y no solamente con una compra esporádica, sino con lealtad permanente en el tiempo y realizando acciones de promoción gratuita traducido en marketing boca-oído, además de generarse relaciones duraderas. Lo manifestado en párrafos precedentes, se conjuga con la afirmación siguiente:

Aunque hay una buena dosis de responsabilidad social en la gestión ordinaria de la empresa que busca el beneficio en competencia con otras, esta puede quedar por debajo de las expectativas de bienestar colectivo sobre todo cuando existen efectos externos en las decisiones de los agentes privados, que el interés particular que mueve la conducta no reconoce y por tanto no interioriza. (Salas, 2009, p. 44)

Por otro lado, y entrando al terreno de lo esencialmente ético, es importante anotar que hoy en día, tiempo en el que "todo está permitido" y que bajo el lema de la libertad, muchas organizaciones esconden su extremo libertinaje, por demás dañino al ser humano y su desarrollo; es pertinente hacer una reflexión acerca del verdadero rol y responsabilidad de la mercadotecnia.

Veamos entonces, que es lo que la mercadotecnia no debe hacer, tomando en cuenta consideraciones éticas:

- Publicidad cargada y sobre cargada de mensajes con alto contenido sexual implícito o explícito, violencia consentida y disfrazada; así como incitaciones inapropiadas.

- Publicidad inadecuada y agresiva dirigida al público más frágil y vulnerable, como son los niños e infantes.

- Publicidad engañosa, mostrando bondades inexistentes de los productos, recurriendo a información inexacta adrede.

- $\quad$ Publicidad cargada de mensajes subliminales que pretenden atacar la vulnerabilidad del ser humano de la forma más salvaje e irracional.

Se podría pensar que con estas limitaciones éticas que debieran ser autoimpuestas por las empresas serias y formales, más que ser una imposición legislativa; se podría estar limitando al extremo la actividad mercadológica. No es así, de ninguna manera, ya que el campo de ésta es extremadamente grande y rico. Incluso podría llegar a ser enriquecedora del desarrollo humano y social. Lo único que se les pide a las empresas es responsabilidad bajo un marco de verdadero sentido humano. 
Definitivamente, una empresa que actúe bajo estrictas normas de responsabilidad social será mejor vista en el mercado y por tanto, mejor aceptada y como consecuencia de esto, tendrá mayor éxito comercial. Ya que responsabilidad social no es una serie de acciones destinadas a limpiar la imagen de la empresa a través de programas publicitarios y relaciones públicas bastante bien elaboradas. Eso no es responsabilidad social. Quizás sea una burda publicidad social y nada más que eso.

Entonces, responsabilidad social es un compromiso serio asumido por la empresa sin ningún interés mayor al de hacer el bien a la sociedad. Dicho compromiso abarca no solamente aspectos materiales como mejorar las condiciones de vida de los trabajadores de las empresas o de los grupos de interés (stakeholders) afectados por la actividad económica y a quienes las empresas están obligadas de atender por razones éticas de gran peso. Sino, también abarca todo el complejo campo de la ética.

Cuando nos referimos a ética no hablamos de valores religiosos sectarios temporales o atemporales. Y es importante aclararlo porque en pleno siglo XXI, pareciera que a algunas personas, incluyendo empresarios, les suena muy extraño y hasta repulsivo hablar de valores éticos con tintes religiosos. Esta animadversión no es otra cosa que una señal de la descomposición moral de nuestros tiempos.

Simplemente, con ética, se habla de valores universales y globales que debieran regir las acciones de todos y de todas las instituciones, incluyendo, por supuesto y obviamente, las empresas.
Entonces, veamos qué es lo que las empresas sí pueden y deben hacer:

- $\quad$ Publicidad utilizando los recursos justos y adecuados, sin recurrir a excesos.

- Publicidad dirigida a un público racional y con capacidad de discernimiento.

- $\quad$ Publicidad honesta, recurriendo a la verdad y a información objetiva acerca de los productos y servicios ofertados.

- $\quad$ Publicidad con mensajes claros, oportunos y veraces.

En correspondencia con lo anterior, no se debe olvidar que la empresa podría obtener diversos beneficios a raíz de sus acciones éticas y responsables. Y es que la sociedad siempre va a observar con óptica constructiva el correcto comportamiento de las empresas y lo contrario ocurrirá cuando se trate de empresas carentes de ética y de responsabilidad.

En ese sentido, los beneficios que las entidades de tipo empresarial y no empresarial pueden obtener son, principalmente, los siguientes.

- Mejora de la imagen organizacional y corporativa.

- Mejora en los niveles de aceptación de los productos y/o servicios; y en consecuencia, en los niveles de venta de los mismos.

- Como consecuencia de lo anterior, mejora en los niveles de utilidades para la empresa. 
- Mayor orgullo en los trabajadores por pertenecer a la organización, y por tanto, un coadyuvante positivo del clima laboral interno.

- Incremento en el valor de las acciones y bonos emitidos por la empresa.

- Mayor credibilidad de la empresa por parte de la sociedad, al mostrar una clara responsabilidad social.

El último punto es fundamental y resume, de cierta forma, toda la filosofía de la ética empresarial, porque la responsabilidad social es tema medular en las organizaciones modernas. Ésta, en muchas ocasiones, se torna abstracta, pero de hecho se puede entender mejor si se materializa en un concepto claro. Por ejemplo, para la Organización Internacional del Trabajo (OIT), la responsabilidad social de la empresa:

Es el conjunto de acciones que toman en consideración las empresas o corporaciones (y organizaciones de toda índole) para que sus actividades y acciones repercutan positivamente sobre la sociedad; además que afirman los principios y valores que las rigen, considerando tanto sus propios métodos y procesos internos como su interrelación con los diversos actores o grupos de interés. Es importante resaltar que La RSE (o RSC) tiene que ser una iniciativa de carácter voluntario. (OIT, 2007, p. 52)

Como se puede apreciar, los beneficios obtenidos gracias a un comportamiento ético por parte de la organización, van en diversas direcciones, desde la más simple como la que se sustenta en el aspecto mate- rial, hasta la más compleja, basada en los componentes más sutiles de la organización y que tocan directamente al ser humano, tanto referido al capital humano o cliente interno, como al cliente externo y a la sociedad en general.

De lo anterior, se desprende que el capital humano que conduce de una u otra forma la organización, o que participa en su operatividad; va a ver acrecentado su orgullo de pertenencia gracias al prestigio ético alcanzado por la empresa. Este es un factor preponderante al momento de medir el clima laboral.

Por tanto, se forma un círculo virtuoso que conduce del orgullo al mejor desenvolvimiento dentro de la organización, y este a su vez, conduce a mejores resultados comerciales, que a su vez se traducen en mayores utilidades. Por tanto, se puede suponer que lo contrario, conduce a la formación de un círculo vicioso, con los consiguientes efectos negativos.

Como corolario, es pertinente observar que hoy en día, en un marco de globalización y elevada competencia y competitividad, la ética empresarial es muy reconocida por todos los grupos de interés. Además, es algo que se deja notar claramente, a pesar de ser un intangible; y es que los intangibles son justamente los activos más valiosos de las organizaciones en la actualidad. Así lo demuestran, por ejemplo, los elevados valores que pueden alcanzar a nivel aureolar, las marcas de prestigio; incluso, sobre sus inversiones en activos fijos.

Es así que las empresas que realmente quieran consolidar su ventaja comparativa 
y posteriormente, su ventaja competitiva estratégica, están en la obligación imperiosa de actuar bajo firmes normas éticas autoimpuestas, sin esperar a que las normas legales las obliguen, ya que la ética es una actitud y una filosofía de vida empresarial, que emerge como fruto de la formación humana permanente a todo nivel y en toda etapa de la vida; y no una imitación ni una actuación impostada como fruto de imposiciones, modas efímeras o presiones externas.

En tal sentido, la ética es principio y fin de toda acción empresarial. Marca con su impronta a toda la organización e influye sobre todos los actores cercanos a la empresa, sean internos o externos. Por tanto, las empresas están obligadas a tomar muy en serio su misión de actores influyentes en la sociedad.

Así pues, la mercadotecnia puede construir o puede destruir. La orientación que se siga será decision cada empresa u organización y quienes juzgarán a las organizaciones y a sus acciones, serán todos los actores de la sociedad.

En ese sentido, responsables del desarrollo humano no son solamente las entidades del gobierno o los organismos destinados a la ayuda social. Responsables somos todos en menor o mayor grado, dependiendo del poder ejercido en y sobre la sociedad. Por esta razón, las empresas, y sobre todo las más grandes, son principales responsables de este desarrollo y por tanto, deben cuidar los valores más preciados que siempre estarán presentes y por tanto, deben ser respetados.
Una empresa que respete a la sociedad en general y en particular a sus grupos de interés; deberá practicar mercadotecnia responsable, respetuosa, ética y que coadyuve al desarrollo de los seres humanos.

Las empresas que han comprendido que la ética no está reñida o separada de las utilidades derivadas de la actividad lucrativa, son las que mayores beneficios presentes y futuros podrán obtener. Las empresas que no buscan el lucro fácil e inmediato a toda costa y que, por el contrario, mantengan una línea de conducta definida dentro de un marco ético, buscando la obtención de ganancias pero a la vez protegiendo la integridad del ser humano; son y serán las empresas de éxito sostenible en el tiempo.

Asimismo, cabe resaltar que el comportamiento ético es un proceso continuo sin un inicio o final definido, pero que, si lo vemos como un proceso, se deberá dar de forma permanente. Tal es el caso, por ejemplo, del proceso mercadológico que se inicia con la investigación de mercados. En tal sentido, Malhotra indica que:

Varios aspectos de la investigación de mercados tienen fuertes implicaciones éticas. Como se explicó antes, la investigación de mercados por lo general es realizada por empresas comerciales (es decir, con fines de lucro) que son organizaciones independientes (proveedores externos) o departamentos dentro de las corporaciones (proveedores internos). La mayoría de la investigación de mercados se realiza para clientes que representan a empresas comerciales. La motivación en las utilidades en ocasiones hace que los investigadores o los clientes pongan en riesgo la objetividad o profesionalismo asociados con el proceso 
de investigación de mercados. A menudo se afirma que en la investigación de mercados hay cuatro interesados: 1. el investigador, 2. el cliente, 3. el encuestado y 4. el público; quienes tienen ciertas responsabilidades entre sí y con el proyecto de investigación. Los problemas éticos surgen cuando los intereses de las partes están en conflicto y cuando uno o más de los interesados no cumplen con sus responsabilidades. (Malhotra, 2008, p. 27-28)

Justamente, es este conflicto de intereses lo que, en diversas oportunidades, genera problemas de orden ético que pueden llegar a generar otros innumerables conflictos. Es más, el autor mencionado, continúa diciendo:

Por ejemplo, si el investigador no sigue los procedimientos adecuados de la investigación de mercados, o si el cliente altera los resultados en la publicidad de la compañía, se están violando las normas éticas. Los problemas éticos se resolverían si los interesados se comportan de manera honorable. (Malhotra, 2008, p. 28)

Por otro lado, es interesante observar que el mercadólogo busca equilibrar los intereses de la sociedad y de la empresa, tal como lo menciona Arellano (2010), quien indica que al hacer una interpretación a mayor profundidad, se muestra que la tarea del mercadólogo dentro de la empresa debe ser en gran medida la de un defensor de los intereses del público frente a los intereses internos empresariales. En tal sentido, los especialistas de marketing o mercadólogos, tienen como misión hacer que la empresa satisfaga adecuadamente las necesidades de los consumidores; por lo tanto, los representa al interior de la misma. Sin embargo, es obvio que el especialista en marketing es parte de la empresa y, en consecuencia, tiene también como interés preservar la salud de su fuente de trabajo. Es así que, la ambivalencia de lealtades lo lleva a encontrar un compromiso entre ambas partes.

Al respecto, desde otra perspectiva, que va más allá del momento presente y del aspecto meramente empresarial, tenemos una visión ética en la que:

La RSE es una estrategia integral corporativa que correctamente planificada, ejecutada y evaluada, contribuye en definitiva a mejorar la competitividad, sostenibilidad y sustentabilidad integral dela organización; detal forma que sefavorece el desarrollo sustentable, al permitir un mejor acceso a mercados, estimulando el desarrollo de su capital humano y grupos de interés variados, así como favoreciendo relaciones sinérgicas con otras organizacionesy con su cadena productiva y, sobre todo, beneficiando su aceptación por parte de toda la sociedad y no solamente de sus clientes o consumidores. (UNIAPAC, 2008, Párr. 18)

Sin embargo, también es adecuado anotar que una empresa que otorga beneficios económicos o materiales sostenibles expresados en rentabilidad a los stakeholders internos y externos, no necesariamente es una empresa responsable. Por tal razón, tal como lo indica la Doctrina Social de la Iglesia, se debe tener en cuenta que cuando una empresa otorga beneficios significa que los factores productivos han sido utilizados adecuadamente (Consejo Pontificio Justicia y Paz, 2005). En definitiva, no se debe olvidar de ninguna manera, el hecho de que no siempre el beneficio económico es un indicador de que la empresa está sirviendo adecuadamente a la sociedad. 
Por último y en la misma línea de lo expresado, es importante dejar en claro que los miembros de una organización empresarial deben ser plenamente conscientes de que la comunidad en la que trabajan representa el objetivo del bien común y no una mera estructura que permite satisfacer exclusivamente los intereses personales de algunos pocos.

De hecho, a la postre, el bien común deberá ser la búsqueda incesante e incansable de la responsabilidad social empresarial.

\section{Conclusiones}

La ética es un componente transversal fundamental en toda actividad empresarial, incluyendo la mercadotecnia. Una empresa que se respete, respetará a la sociedad. Por ello, toda empresa tiene la obligación de velar por el bien común, salvaguardando a los públicos más vulnerables, como es el caso de los niños.

Es perfectamente posible y factible dirigir organizaciones en un maco de ética y responsabilidad social. Incluso, las empresas y organizaciones en general que incorporen estos conceptos en sus políticas más comunes y usuales, podrán apreciar clara y rápidamente sus buenos resultados.

La veracidad en la mercadotecnia siempre dará buenos frutos, aunque no necesariamente genere importantes utilidades en el corto plazo. Sin embargo, tendrá un efecto inmediato en la generación de confianza entre los actores del mercado y todos los stakeholders.
Recursos facilistas como la publicidad engañosa, obscena y sobrecargada de mensajes denigrantes, así como los mensajes subliminales y publicidad inadecuada dirigida a públicos vulnerables, como el infantil; conducen siempre al deterioro de la imagen de la empresa.

\section{Referencias}

Arellano, R. (2010). "Marketing: Enfoque América Latina”. México: Pearson Educación.

Chiavenato, I. (2005). "Introducción a la teoría general de la administración”. México: McGraw Hill.

Consejo Pontificio Justicia y Paz. (2005). "Compendio de la Doctrina Social de la Iglesia”. Roma: Librería Editrice.

Kotler, P. y Armstrong, G. (2013). "Fundamentos de mercadotecnia”, México: Pearson Prentice Hall.

Malhotra, N. (2008). “Investigación de Mercados”. México: Pearson Educación.

Organización Internacional del trabajo (OIT). (2007). "Guía de recursos sobre Responsabilidad Social de la Empresa”. México: OIT.

Salas, V. y otros (2009). "Responsabilidad social: Una reflexión global sobre la RSE”. Madrid: Pearson Prentice Hall.

Uniapac Foundation. (2008). "La Rentabilidad de los valores”. Montevideo: Uniapac Latinoamericana. 